\title{
Experimental Correlations Nu vs Gr.Pr at Varying Widths for Convective Heat Flow Through a Large Aperture in a Full Scale Enclosed Space
}

\author{
Sebbar Yazid Youcef ${ }^{*}$, Belaidi Abdelkader ${ }^{2}$ \\ ${ }^{1}$ Mechanical Engineering Department, Ecole Nationale Polytechnique Oran, Bp 1523, Oran El-Menouar 31000, Algeria \\ ${ }^{2}$ Physics Department, Ecole Nationale Polytechnique Oran, Bp 1523, Oran El-Menouar 31000, Algeria
}

Corresponding Author Email: yazid.sebbar@enp-oran.dz

https://doi.org/10.18280/ijht.390528

Received: 25 June 2021

Accepted: 12 October 2021

\section{Keywords:}

calorimetric chamber, convection through opening, door aspect ratio

\begin{abstract}
Convective heat transfer through a large aperture has been studied theoretically and experimentally using reduced scale models for many years. This paper describes the effect of the width of a large opening on the convective heat flow in an enclosure for $5.6 \times 10^{8}<$ Rayleigh number $(R a)<2.8 \times 10^{10}$. In our case a full scale realistic calorimetric chamber $(5.5 \mathrm{~m} \times 2.5 \mathrm{~m} \times 2.5 \mathrm{~m})$ was used in this study. This chamber contains two zones connected by a large aperture of height $\mathrm{H}$. A hot and cold wall on each side of the aperture will create a temperature difference between the two zones. Empirical equations are expressed in terms of varying door aspect ratio $A_{D S}$, i.e.: $\frac{N u}{P r}=\left(\alpha+\beta \frac{W}{H}\right) * G r^{b}$, at various temperature differences between the two zones. It was clearly found that as the width decreases the convective flux increases substantially. The instability of the air flow due to the apparition of a small turbulence increased when the opening width gets larger. It was also noticed that the neutral axis (air velocity $=0$ ) goes up when the width of the opening decreases resulting in an acceleration of the air flow above the neutral axis. The liability of these experimental results could be useful for the validation of simulation models.
\end{abstract}

\section{THE STATE OF THE ART AND OBJECTIVES OF THIS STUDY}

The air flow crossing a large opening in a building (door or window) have a great influence in the heat and mass transfer between two residential zones.

We are interested mainly in the air flow produced by natural convection. It is important today for architects to have a clear idea about the quantity of heat flow by convection that crosses doorways or large apertures separating two zones at different temperatures in buildings in order to obtain an optimum design in terms of heat loss and thermal comfort. A lot of work in this field has been carried out during the past years but using reduced scale models and generally the results are expressed in terms of Nusselt $(\mathrm{Nu})$, Grashoff (Gr) and Prandlt (Pr) numbers. The mathematical models were greatly simplified considering one-dimensional laminar flow.

As the air flow through the opening shows some instability, authors consider a turbulent flow and they usually use the k- $\varepsilon$ model which is not a good adaptation for low Reynold (Re). In fact, the k- $\varepsilon$ model has been tailored specifically for planar shear layers and recirculating flows. It is usually useful for free-shear layer flows with relatively small pressure gradients as well as in confined flows where the Reynolds shear stresses are most important.

Indeed, the problem of natural convection through an opening is in the limit of laminar and turbulent flow, and Davidson [1] says that actually, we dispose of some models of turbulence for low Re but, they can be used only in the vicinity of the walls and not in the free layer. In the experimental field, we found some experiments in reduced scale [2] and also in real scale [3, 4], the results obtained in both cases were not always in good agreements. The full scale model will measure direct values whereas the reduced scale will use similarity laws that don't take necessarily into account all the parameters.

According to Baraka's review [5] the $\boldsymbol{a}$ coefficient in the equation $\mathrm{Nu}=\mathrm{a}^{*} \operatorname{Pr}^{*} \mathrm{Gr}^{\mathrm{b}}$ is largely dependent upon the value of $\Delta \mathrm{T}$ between the hot and cold zone. Through a large aperture, Sanvicente et al. [6] showed clearly that the convective heat flow was neither fully laminar nor turbulent.

Oztop et al. [7] have used finite volume method in order to perform three-dimensional computational analysis of entropy generation due to natural convection in partially open enclosure. The study has been performed for different governing parameters such as opening ratio $0.25 \leq h \leq 0.75$, center of opening $0.25 \leq d \leq 0.75$ and Rayleigh number $10^{3} \leq$ $R a \leq 10^{5}$. It was observed that edge of openings was the most effective parameter on entropy generation and after comparing many cases, both the highest heat transfer and entropy generation were observed for the fully opened cavity.

Doghmi et al. [8] have studied numerically mixed convection heat transfer in a 3-D ventilated cavity. The results are presented in terms of streamlines, temperature distribution, velocity fields, and average Nusselt number for different combinations of thermal and geometrical controlling parameters, namely, Reynolds number, $\mathrm{Re}=100$, Richardson number $(0.01 \leq \mathrm{Ri} \leq 10)$, relative height of the openings $(\mathrm{B}=$ $\mathrm{h} / \mathrm{L}=1 / 8)$ and relative width $(0.5 \leq \mathrm{A}=\mathrm{w} / \mathrm{L} \leq 1)$.

In order to get the best heat transfer between the two zones, various positions of the active walls were obtained using a numerical simulation for different aspect ratios of the doorway $1.5,2$ and 4 in a partially heated enclosure, at $10^{3}<R a<10^{6}$ and 
Prandlt number $=0.71$ [9]. More recently, Abaas et al. [10] investigated numerically an enclosure at the base and an opposite outlet at the top using finite element method. The heat was applied to the side wall of the enclosure away from the inlet opening at various Richardson numbers. Average and local Nusselt number was determined during the investigation as well as the streamlines and the isothermal patterns. AlZuhairy et al. [11] Performed a numerical investigation of the convection heat transfer in a square cavity that have been vented vertically. Different values of Reynolds number were used $(50,100,200$, and 250) with three different opening to side length ratio $(\mathrm{S} / \mathrm{L})$ in the cavity $(0.1,0.2$, and 0.3$)$. The results showed that as Reynolds number increase inside the cavity, the Nusselt number increased.

In the literature it is generally assumed that the temperature in each zone is homogenous which is a totally wrong assumption. Indeed, there are temperature gradients in all $\mathrm{x}, \mathrm{y}$ and $\mathrm{z}$ directions. This is why it remains the question of which is the best temperature difference $\Delta \mathrm{T}$ to choose between the hot and cold zone in order to express the best correlation. Sebbar [12] has experimented in a full scale partitioned chamber the influence of the choice of the temperature difference upon the value of the convective heat flow through a large aperture; he presented a series of empirical relations in terms of various temperature differences used.

The objective of our present experimental work is to develop convective heat transfer equations through a large realistic opening. These empirical relations will clearly show the impact of the opening width i.e., different $A_{D S} 0.690 \mathrm{~m}<$ width $<1.265 \mathrm{~m}$ maintaining the height of the aperture $\mathrm{H}$ constant on the convective heat flow between the hot and cold zone. The experiment was carried out for $5.6 \times 10^{8}<R a<$ $2.8 \times 10^{10}$, the air temperature difference between the two zones was increased from $0.5^{\circ} \mathrm{C}$ to $6.5^{\circ} \mathrm{C}$. Study state was maintained inside the chamber using a regulating system at different heating power (from $100 \mathrm{~W}$ to $1300 \mathrm{~W}$ ).

\section{THE EXPERIMENTAL ARRANGEMENT}

\subsection{The calorimetric chamber}

Figure 1 shows the calorimetric chamber where experiments were performed. The dimensions of the chamber are $5.5 \mathrm{~m} \times 2.5 \mathrm{~m} \times 2.5 \mathrm{~m}$ with a central partition having a large opening of height $\mathrm{H}=2.05 \mathrm{~m}$ with an adjustable opening varying from $0.690 \mathrm{~m}$ to $1.265 \mathrm{~m}$. This chamber is made perfectly adiabatic using isolating polystyrene foam and an air envelop contained in an extra enclosure. The temperature of the air envelop is controlled in order to ensure study state inside the chamber.

Two opposite walls on each side of the partition are mounted in order to create a temperature difference between the two zones one is heated uniformly whereas the other is being cooled permanently.

\subsection{Experimental measuring techniques}

The temperatures of the air at various positions in the space of the chamber as well as the temperature of the surface of the walls were measured using 140 thermocouples scattered at various positions inside the volume of the calorimeter. In the plane of the aperture sensors were used to measure air velocity (in the horizontal and vertical directions).

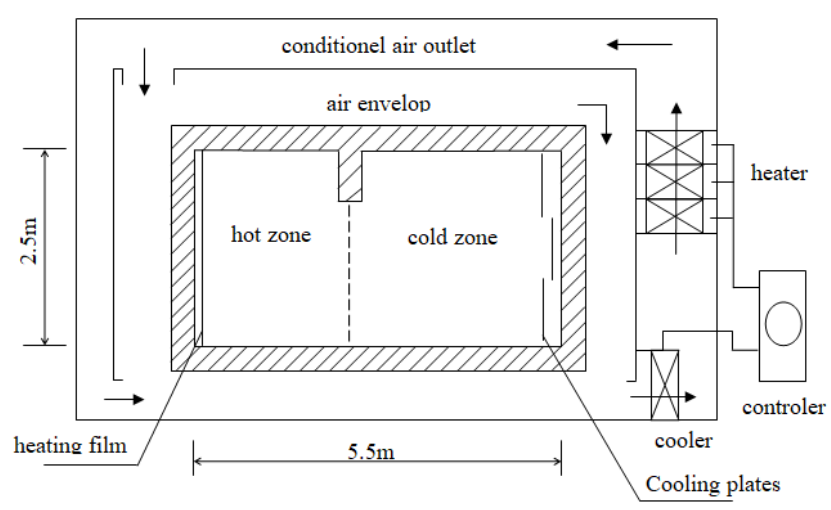

Figure 1. The experimental set up-the calorimetric enclosure

\subsection{Choice of temperature differences used in our analysis}

$\Delta T_{\text {wall }}$ : temperature difference between hot and cold walls.

$\Delta T_{\text {mean-door }}$ : temperature difference at the plane of opening between average temperatures above and under the midpoint of the door.

$\Delta T_{\max -\min }$ : difference between the highest and lowest temperatures measured above and under the axis of the doorway respectively.

$\Delta T_{\text {centr.col }}$ : difference between average temperatures measured by thermocouples placed on columns positioned centrally in the hot and cold zones.

$\Delta T_{\text {all.col.par }}$ : difference between average temperatures taken on parallel columns positioned on each side of the partition.

\section{RESULTS OBTAINED}

For Rayleigh number comprise between $5.6 \times 10^{8}<$ Rayleigh number $(R a)<2.8 \times 10^{10}$ and for net convective heat transfers $\dot{q}_{\text {conv }}$ between the hot and cold zone ranging from $71 \mathrm{~W}$ to $952 \mathrm{~W}$, more than 30 tests were performed at various aperture widths comprise between $0.690 \mathrm{~m}$ and $1.265 \mathrm{~m}$.

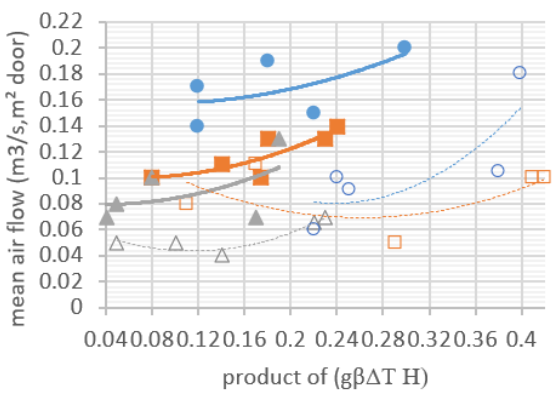

$$
\begin{aligned}
& \text { - serie II width } \mathrm{W}=0.685 \mathrm{~m} \text { (measured) } \\
& \text { - serie III width } \mathrm{W}=0.98 \mathrm{~m} \text { (measured) } \\
& \Delta \text { serie IV width } \mathrm{W}=1.26 \mathrm{~m} \text { (measured) } \\
& \triangle \text { serie I+IV width } \mathrm{W}=1,26 \mathrm{~m} \\
& \square \text { serie III width } \mathrm{W}=0,98 \mathrm{~m} \\
& \text { o serie II width } \mathrm{W}=0,685 \mathrm{~m}
\end{aligned}
$$

Figure 2. Comparison between calculated and measured values of mean air flow through the door $-\Delta T_{\text {door max min }}$ for various door width

The Grashoff and Nusselt numbers were calculated using the height $\mathrm{H}$ of the opening as characteristic length. As an example the influence of the door width on the air flow is clearly shown on Figure 2. This figure also indicates the 
comparison between the calculated volume flow rate and the measured one based on velocity values obtained through the aperture. It can be clearly observed that the measured and calculated curves are very close for all aperture width. These curves were obtained on the basis of $\mathrm{Gr}$ calculated using the $\Delta T_{\min -\max }$ i.e. the difference between the maximum and minimum temperatures above and under the axis of the opening respectively.

When plotting $\mathrm{Nu} / \mathrm{Pr}$ vs $\mathrm{Gr}$, in Figures 3 and 4, we can easily notice that as the width decreases the convective flux increases substantially. In order to calculate Grashoff number $\Delta T_{\text {centr.col }}$ and $\Delta T_{\text {mean door }}$ were used in these cases.

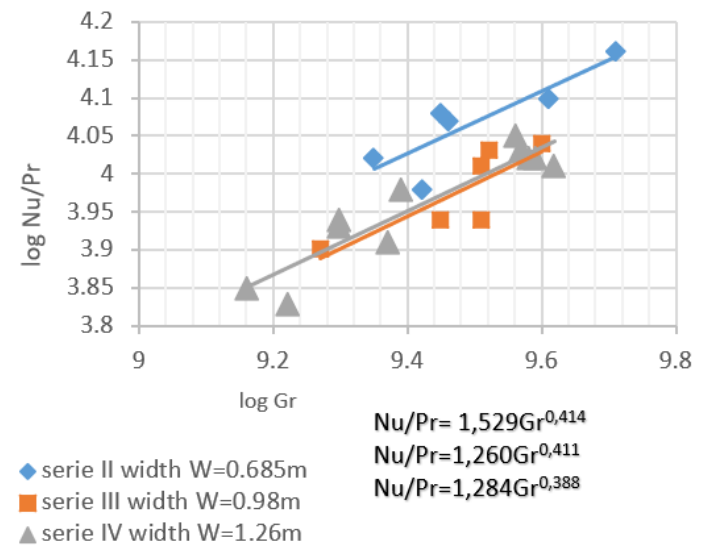

Figure 3. Heat flux at various Grashoff number for different opening width $-\Delta T_{\text {centr.col }}$

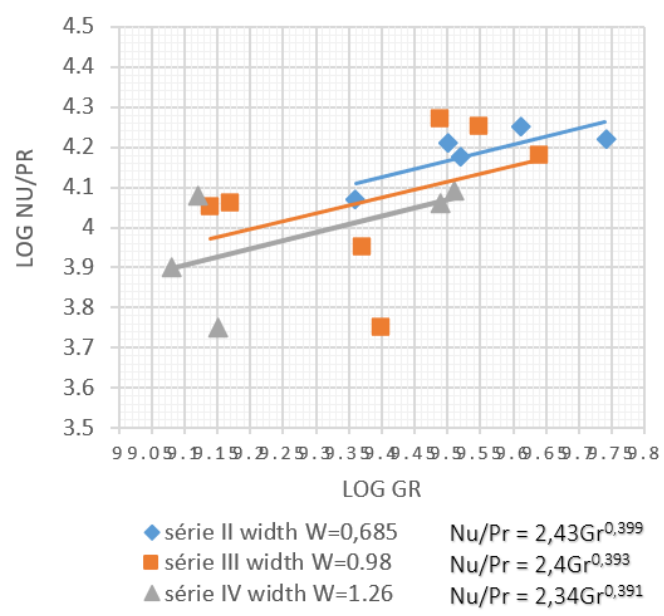

Figure 4. Heat flux at various Grashoff number for different opening width $-\Delta T_{\text {mean door }}$

In Table 1 the influence of the opening width on the convective heat flux is stated for different temperature differences used to determine the convective heat transfer. The aspect door ration $\mathrm{W} / \mathrm{H}$ is used, where $\mathrm{W}$ is the opening width.

Table 1. Some experiment correlations at various aspect ratio

$$
A_{D S}=\frac{W}{H} \text { for } \mathrm{Nu} / \mathrm{Pr}=\mathrm{f}(\mathrm{Gr})
$$

\begin{tabular}{cc}
\hline $\begin{array}{c}\text { Temperature } \\
\text { differences }\end{array}$ & Criteria equations for different \\
\hline$T_{\text {Wall }}$ & $(4.01-4.470 \mathrm{~W} / \mathrm{H}) G r^{0.27}$ \\
$T_{\text {col.centr }}$ & $(1.83-1.01 \mathrm{~W} / \mathrm{H}) G r^{0.41}$ \\
$T_{\text {door mean }}$ & $(2.54-0.32 \mathrm{~W} / \mathrm{H}) G r^{0.39}$ \\
$T_{\text {door } \max \text { min }}$ & $(1.666-0.728 \mathrm{~W} / \mathrm{H}) G r^{0.39}$ \\
$T_{\text {all col }}$ & $(1.93-1.03 \mathrm{~W} / \mathrm{H}) G r^{0.41}$ \\
\hline Par &
\end{tabular}

The values of the exponent $\mathbf{b}$ found in the above table are approximately identical $b \approx 0,40$ for all temperature differences taken except when the difference between the hot and cold walls are considered where $b=0.27$ which corresponds to the general normal results [13].

Table 2. Some experimental correlations between $\mathrm{Nu}, \mathrm{Pr}$ and Gr at various $\Delta \mathrm{T}$

\begin{tabular}{cccc}
\hline Openings width & 1.265 & 0.979 & 0.690 \\
\hline Nu/Pr & $\mathbf{5 0 0 - 1 1 0 0}$ & $\mathbf{9 0 0 -}$ & $\mathbf{1 3 0 0 -}$ \\
Walls & 1.353 & $\mathbf{1 3 0 0}$ & $\mathbf{2 0 0 0}$ \\
$T_{\text {wall }}$ & $G r^{0.267}$ & 1.692 & 2.597 \\
& & $G r^{0.271}$ & $G r^{0.273}$ \\
Nu/Pr & $\mathbf{5 0 0 0}-$ & $\mathbf{6 0 0 0}-$ & $\mathbf{9 0 0 0 -}$ \\
Column & $\mathbf{1 2 0 0 0}$ & $\mathbf{1 2 0 0 0}$ & $\mathbf{1 6 0 0 0}$ \\
$T_{\text {centr-col }}$ & 1.284 & 1.260 & 1.529 \\
Nu/Pr & $G r^{0.388}$ & $G r^{0.411}$ & $G r^{0.414}$ \\
Door mean & $\mathbf{6 5 0 0 -}$ & $\mathbf{1 0 0 0 0 -}$ & $\mathbf{9 0 0 0 -}$ \\
$T_{\text {door mean }}$ & $2.34 G r^{0.381}$ & $\mathbf{1 4 0 0 0}$ & $\mathbf{1 6 0 0 0}$ \\
& & $G r^{0.393}$ & $G r^{0.399}$ \\
Nu/Pr & $\mathbf{4 0 0 0 - 8 5 0 0}$ & $\mathbf{6 5 0 0 -}$ & $\mathbf{5 0 0 0 -}$ \\
Door max min & 1.232 & $\mathbf{8 5 0 0}$ & $\mathbf{1 3 0 0 0}$ \\
$T_{\text {door max min }}$ & $G r^{0.390}$ & 1.296 & 1.43 \\
& & $G r^{0.392}$ & $G r^{0.397}$ \\
Nu/Pr & $\mathbf{4 5 0 0 -}$ & $\mathbf{8 0 0 0 -}$ & $\mathbf{1 0 0 0 0}-$ \\
All col. & $\mathbf{1 1 0 0 0}$ & $\mathbf{1 2 5 0 0}$ & $\mathbf{1 5 0 0 0}$ \\
$T_{\text {Col.para }}$ & $1.328 G r^{0.40}$ & 1.387 & 1.616 \\
& & $G r^{0.410}$ & $G r^{0.413}$ \\
\hline
\end{tabular}

The above table (Table 2) shows at various Nusselt numbers corresponding to different power injection levels in the hot wall, equations resulting from experimental data of $\mathrm{Nu} / \mathrm{Pr}$ in terms of $\mathrm{a}^{*} G r^{b}$. We can clearly see that the highest $\mathbf{a}$ and $\mathbf{b}$ coefficients appear for the smallest width of the opening.

Figures 5, 6 and 7 show the velocity profiles of the air through the opening at different width, the position of the neutral axis corresponds to $\mathrm{v}=0 \mathrm{~cm} / \mathrm{s}$. Its position lays between $0,5 \mathrm{~m}$ and $0,7 \mathrm{~m}$ depending on the opening width taken. It can be clearly observed that the neutral axis goes up as the opening width gets smaller. In all cases, the position of this axis is never at the mid-height of the opening as it is usually admitted. This can be explained by the fact that the Bernoulli model used assuming steady state 2-D and ideal flow was not quite appropriate. In fact it seems that the flow through the doorway is 3-D and slightly unsteady. Some low turbulence appears as it will be seen later in this paper. As expected we measured higher velocities for the narrowest opening.

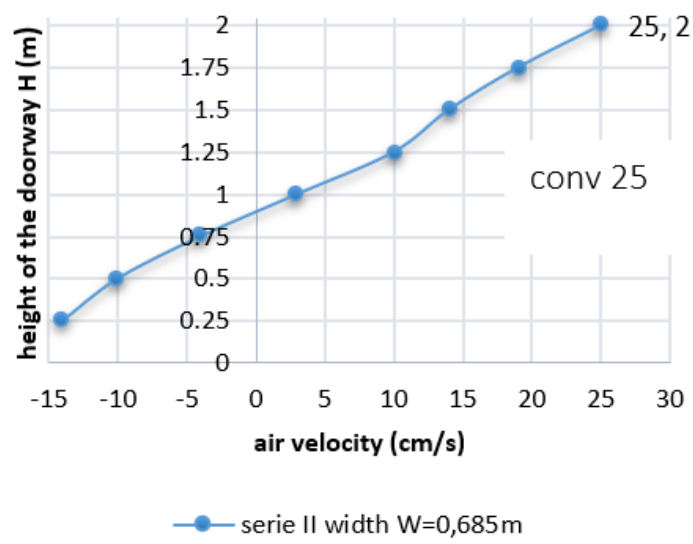

Figure 5. Variation of the velocity of the air in the plane of the opening. $(\mathrm{W}=0.690 \mathrm{~m})$ 


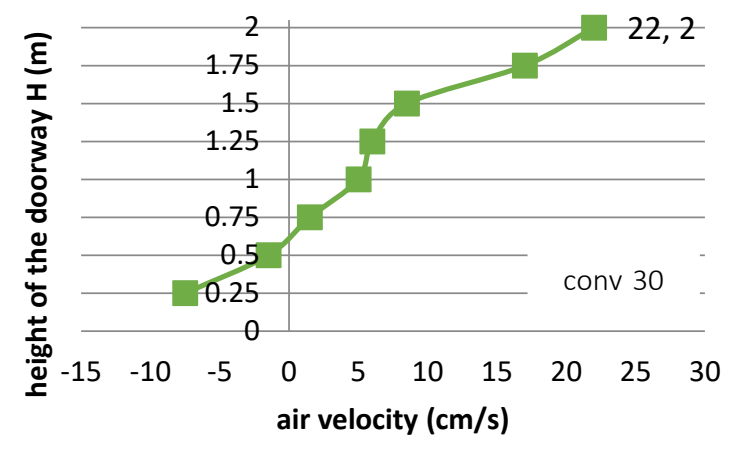

- serie III width $\mathrm{W}=0,98 \mathrm{~m}$

Figure 6. Variation of the velocity of the air in the plane of the opening. $(\mathrm{W}=0.979 \mathrm{~m})$

Velocity measurements at the opening show that the air flow is unstable (Figure 8 and 9) and therefore the conventional methods based on laminar flow analysis probably need to be improved. Indeed, the problem of natural convection through an opening is in the limit of laminar and turbulent flow.

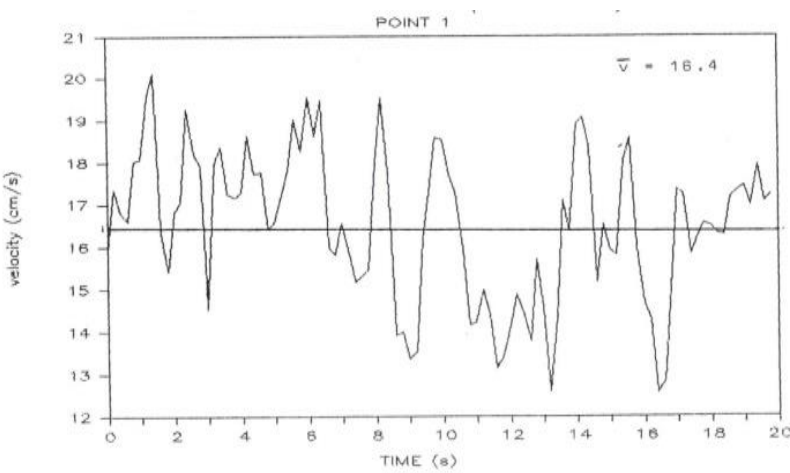

8a: Height $\mathrm{H}=0.25 \mathrm{~m}$

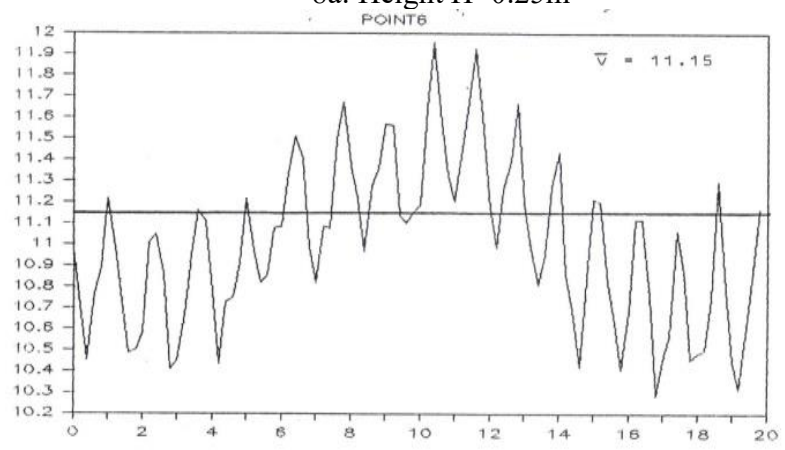

8c: Height $\mathrm{H}=1.5 \mathrm{~m}$

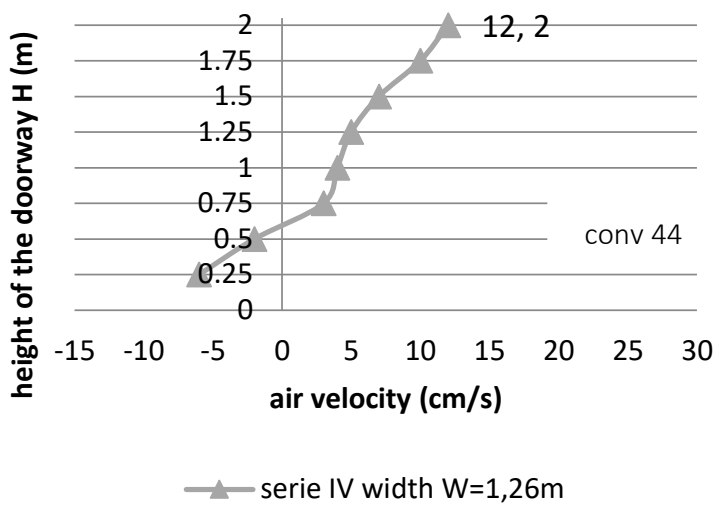

Figure 7. Variation of the velocity of the air in the plane of the opening. $(\mathrm{W}=1.265 \mathrm{~m})$

Davidson [1] states that we dispose of some models of turbulence for lower Re but they can only be used in the vicinity of the walls and not in the free layer. Comparing Figures 8 and 9 we can easily see that the instability of the flow increases with the width of the door opening. That can be explained by the fact that we have lower Reynolds number for wider openings.

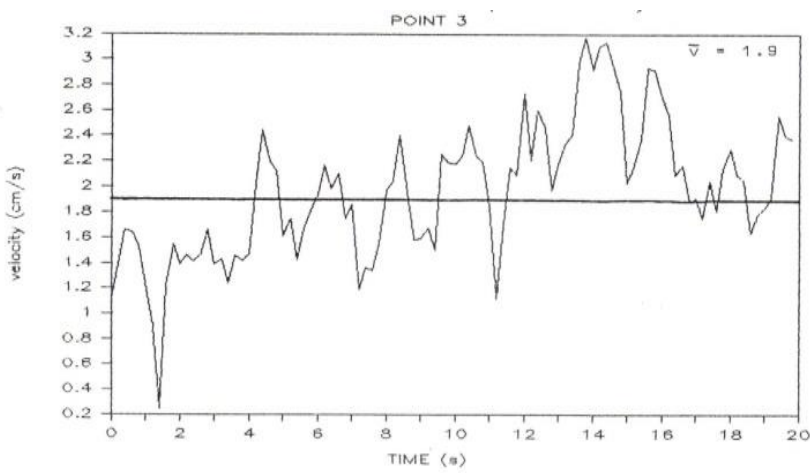

8b: Height $\mathrm{H}=0.75 \mathrm{~m}$

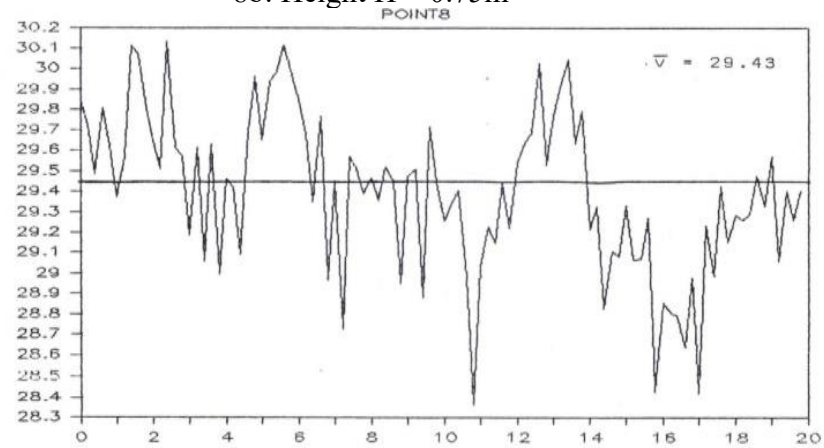

$8 \mathrm{~d}$ : Height $\mathrm{H}=2.0 \mathrm{~m}$

Figure 8. $W=0.690 \mathrm{~m}$. Velocity measurements at different heights on the plane of the opening showing slight turbulence at low $\operatorname{Re}$

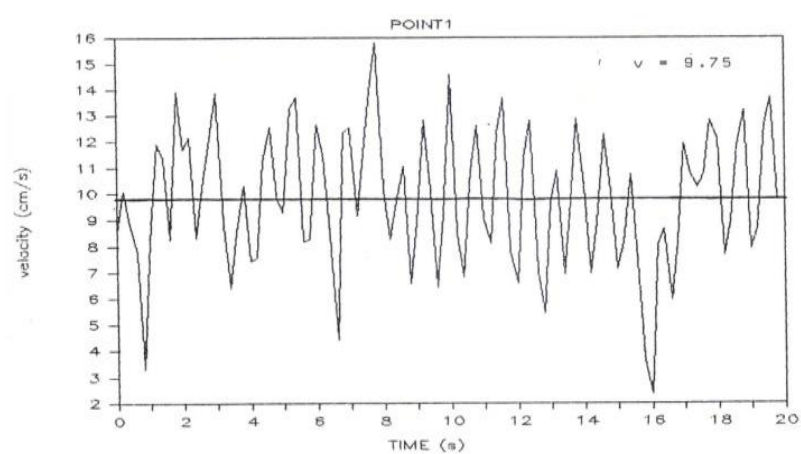

9a: Height $\mathrm{H}=0.25 \mathrm{~m}$

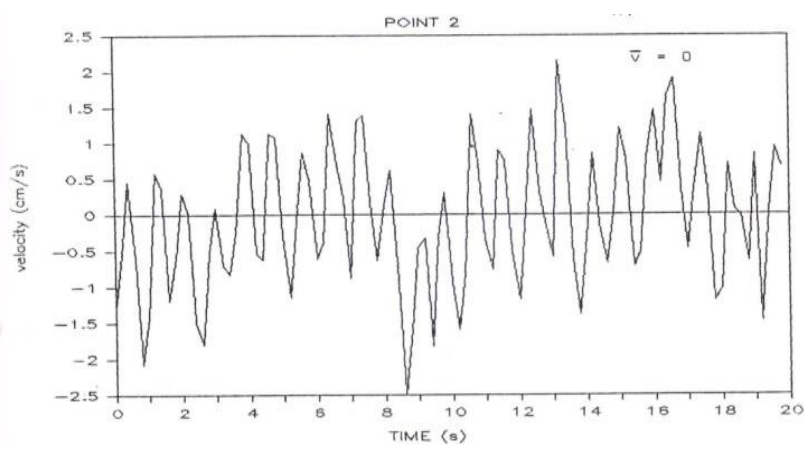

9b: Height $\mathrm{H}=0.5 \mathrm{~m}$ 


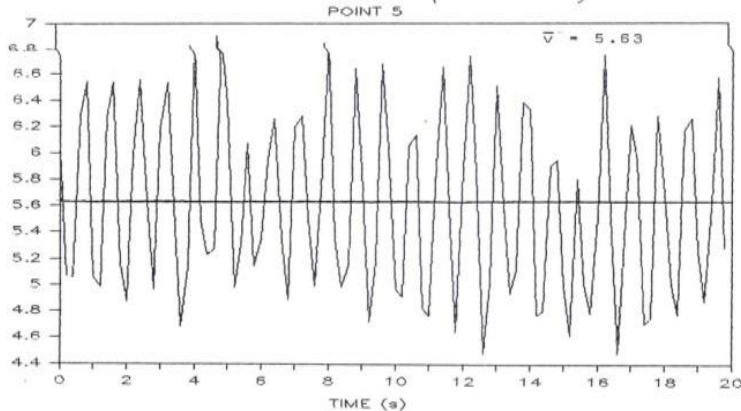

9c: Height $\mathrm{H}=1.25 \mathrm{~m}$

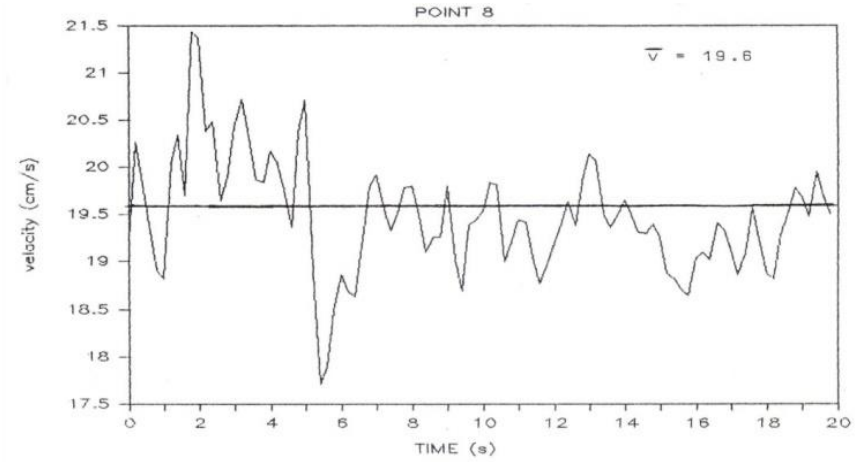

9d: Height $\mathrm{H}=2,0 \mathrm{~m}$

Figure 9. $\mathrm{W}=1.265 \mathrm{~m}$. Velocity measurements at different heights on the plane of the opening showing slight turbulence at low

\section{GENERAL CONCLUSION}

As a result of this experimental work, empirical relations were obtained for the convective heat transfer through a large opening separating a hot and cold zone in Tables 1 and 2 . These relations take into account the influence of the width $\mathrm{W}$ of the opening on the heat transfer. Some experiment correlations at various aspect ratio $A_{D S}=\frac{W}{H}$ for $\mathrm{Nu} / \mathrm{Pr}=\mathrm{f}(\mathrm{Gr})$ are presented in Table 1 in the form of $\mathrm{Nu} / \mathrm{Pr}=(\alpha+\beta \mathrm{W} / \mathrm{H}) \mathrm{Gr}^{\mathrm{b}}$, these relations correspond to various temperature differences taken between different positions in the hot and cold zone. The influence of the door aspect ratio ADs clearly appears.

From Table 2, where the relation $\mathrm{Nu} / \mathrm{Pr}=\mathrm{a}^{*} \mathrm{Gr}^{\mathrm{b}}$ is presented, we can note that the coefficient $\boldsymbol{a}$ has the highest value corresponding to the smallest width of the door opening. As the width increases the value of $\boldsymbol{a}$ decreases for all temperature differences we consider. The exponent $\boldsymbol{b}$ remains more or less constant for all cases i.e. $0.39<\mathrm{b}<0.41$ at the exception of the case where $\Delta \mathrm{T}_{\text {wall }}$ is considered $\boldsymbol{b}=0.27$.

Knowing that:

$$
\Delta T_{\text {wall }}>\Delta T_{\text {max }-\min }>\Delta T_{\text {cent.col }}>\Delta T_{\text {mean door }}
$$

the best results were obtained when calculating the air volume flow rate per unit area by using the door mean temperature difference $\Delta T_{\text {mea door }}$ in the plane of opening. This was confirmed by comparing the net heat balance between the two zones and the convective heat flux through the opening using the measured air flow rate.

It was clearly observed that as the opening width decreases the convective flux increases substantially. The instability of the air flow due to the apparition of a small turbulence increased when the opening width gets larger. It was also noticed that the neutral axis (air velocity $=0$ ) goes up when the width of the opening decreases resulting in an acceleration of the air flow above the neutral axis.

These experimental results can be used to validate numerical simulation models and those of experiments performed on reduced scale models. Of course as this investigation took place in a realistic chamber, all results can be taken for building design purposes.

\section{ACKNOWLEDGMENT}

The authors wish to thank Professor Jean Lebrun of laboratory of thermodynamics at liege university for his advices and full guidance throughout this project.

\section{REFERENCES}

[1] Davidson, L. (1989). Numerical simulation of turbulent flow in ventilated rooms. Department of Applied Thermodynamics and Fluid Mechanics, Chalmers tekniska högskola.

[2] Nansteel, M.W., Greif, R. (1981). Natural convection in undivided and partially divided rectangular enclosures. Journal of Heat Transfer, 103(4): 623-629. https://doi.org/10.1115/1.3244518

[3] Mahajan, B.M. (1987). Measurement of interzonal heat and mass transfer by natural convection. Solar Energy, 38(6): 437-446. $\quad$ https://doi.org/10.1016/0038092X(87)90025-9

[4] Allard, F., Bonnotte, D., Liman, K. (1990). Air flow through large openings: Experimental study of the discharge coefficient. In Internal Report CETHILL-URA CNRS 1372, INSA DE LYON, Batiment 307, Annex 20 Meeting.

[5] Brakat, S.A. (1986). Inter-zone convective heat transfer in buildings: A revue. In Int. Climat Architecture Congress, pp. 1-3.

[6] Sanvicente, E., Giroux-Julien, S., Ménézo, C., Bouia, H. (2013). Transitional natural convection flow and heat transfer in an open channel. International Journal of Thermal Sciences, 63: 87-104. https://doi.org/10.1016/j.ijthermalsci.2012.07.004

[7] Oztop, H.F., Almeshaal, M.A., Kolsi, L., Rashidi, M.M., Ali, M.E. (2019). Natural convection and irreversibility evaluation in a cubic cavity with partial opening in both top and bottom sides. Entropy, 21(2): 116. https://doi.org/10.3390/e21020116

[8] Doghmi, H., Abourida, B., Belarche, L., Sannad, M., Ouzaouit, M. (2018). Effect of the inlet opening on mixed convection inside a 3-D ventilated cavity. Thermal Science, 22(6): 2413-2424. https://doi.org/10.2298/TSCI170126121D

[9] Mahapatra, P.S., Manna, N.K., Ghosh, K. (2015). Effect of active wall location in a partially heated enclosure. International Communications in Heat and Mass Transfer, 61: 69-77. https://doi.org/10.1016/j.icheatmasstransfer.2014.12.01 9 
[10] Abaas, A.A.A.N., Hussain, H.M., Saieed, A.N.A., Habeeb, L.J., Jalghaf, H.K. (2020). Computational investigation on free and forced convection inside an enclosure. Journal of Mechanical Engineering Research and Developments, 43(5): 318-331.

[11] Al-Zuhairy, R.C., Alturaihi, M.H., Abd Ali, F.A.M., Habeeb, L.J. (2020). Numerical investigation of heat transfer in enclosed square cavity. Journal of Mechanical Engineering Research and Developments, 43(6): 388403.

[12] Sebbar, Y.Y. (2015). Experimental study of convective heat flow through a large opening in a partitionned enclosure. International Journal of Heat and Technology, 33(4): 211-216. http://dx.doi.org/10.18280/ijht.330428

[13] McAdams, W.H. (1959). Heat Transmission. 3rd edition. MC Graw - Hill, New York.

\section{NOMENCLATURE}

ADs Door Aspect ratio $\mathrm{W} / \mathrm{H}$

a coefficient

b exponent

$\mathrm{H}$ height of the opening (m)

$h_{n} \quad$ height of neutral axis

$\mathrm{T}$ temperature $(\mathrm{K})$

$\dot{q} \quad$ heat flow rate $(\mathrm{W})$

$\mathrm{v} \quad$ air velocity $(\mathrm{m} / \mathrm{s})$

W width of the opening (m)

\section{Greek symbols}

$\begin{array}{ll}\alpha & \text { coefficient } \\ \beta & \text { coefficient } \\ \Delta & \text { difference }\end{array}$

